\title{
Progressive Muscle Relaxation, Spiritual Guided Imagery, Music on Coping and Resilience among Cancer Patients who Undergo Chemotherapy
}

\section{Sutinah, Maulani, Rasyidah Azhari, and Isti Harkomah}

Program Studi IImu Keperawatan, Sekolah Tinggi Ilmu Kesehatan Harapan Ibu, Jambi, Indonesia ORCID:

Sutinah: https://orcid.org/0000-0001-7032-7437

\section{Abstract}

Cancer diagnosis and chemotherapy cause physical, psychological, social, and spiritual problems for sufferers. Cancer patients who experience emotional distress need to be appropriately managed through good coping mechanisms. The purpose of this study was to analyze the effectiveness of progressive muscle relaxation, spiritual guided imagery and music for coping and resilience of cancer patients undergoing chemotherapy. This study was a quasi-experimental design. A total of 62 respondents (intervention and control groups) were determined using a purposive sampling technique. The independent variable was Progressive Muscle Relaxation therapy with Spiritual Guided Imagery and Music. Meanwhile, the dependent variable was coping and resilience. The instrument used The-14 items Resilience Scale and The Cancer Coping Questionnaire. Data were analyzed using the General Linear Model Repeated Measures. The results showed that coping mechanisms improved in the first week, while resilience was only developed in the second week after being given the intervention. The results of statistical tests are less than a p-value $<0.05$. In general, there were significant differences in the effect of coping scores and resilience between the treatment group and the control group after being given therapy. The combination of Progressive Muscle Relaxation therapy with Spiritual Guided Imagery and Music can improve coping and resilience in cancer patients undergoing chemotherapy. The government and health workers are expected to consider these findings that can be used as interventions to enhance coping and resilience.

Selection and Peer-review under the responsibility of the IVCN Conference Committee.

\section{S OPEN ACCESS}

\section{Introduction}

Cancer is a group of diseases in which malignant cells grow out of control and spread to other parts of the body (1). Current cancer management efforts are carried out in various ways, namely, surgery followed by radiotherapy, treatment with three combinations, 
namely surgery, radiation, and chemotherapy (2). Cancer diagnosis and chemotherapy caused problems in physical, psychological, social, and spiritual aspects for sufferers (3). The data showed that more than $70 \%$ of respondents reported experiencing depression because of their cancer. Cancer patients who experience psychological stress in these conditions substantially reduce their quality of life and have the potential to interfere with treatment adherence, therefore, it is very important to properly treat the emotional stress of people living with cancer (4). Patients with cancer may experience impaired coping mechanisms (5). Individuals who are unable to deal with their disease tend to avoid and experience developmental disorders of the disease (4)

Adaptive coping in cancer sufferers can be achieved by minimizing and even eliminating the stressors that cause it (6). A suitable coping mechanism in cancer patients undergoing chemotherapy will increase their resilience. Resilience includes positive emotions, flexible thinking such as acceptance, active coping, and spirituality (4). Preliminary studies found that there were patients who dropped out of chemotherapy. This is because patients are unable to withstand the harsh side effects of chemotherapy, hopelessness, and fear of the shadow of death, and some even are depressed and cannot afford chemotherapy treatment.

One way for newly diagnosed cancer sufferers to control emotional stress is with an excellent coping mechanism (7) and relaxation techniques (8). Some of the methods that can be done are Progressive Muscle Relaxation (PMR) and Guided Imagery and Music (GIM) techniques. Previous studies have proven the effectiveness of PMR in several diseases, including improvement in the quality of life of prostate cancer patients (9), reduce depression, anxiety, and length of treatment in breast cancer patients after undergoing radical mastectomy (10) and can reduce anxiety and improve mood (11). Besides, the spiritual aspect has become part of the need for healing with a spiritual approach to the treatment of diseases, physical and mental disorders, intending to cultivate happiness, security, peace of mind, and guidance for the emergence of faith $(12,13)$.

The choice of appropriate therapy is also essential in increasing the resilience of cancer patients undergoing chemotherapy. In this study, researchers will add a spiritual aspect to the Guided Imagery and music intervention for coping and strength of cancer patients undergoing chemotherapy. PMR and GIM are a complementary therapeutic combination that involves elements of the mind-body and spirit. The purpose of this study was to analyze the progressive muscle relaxation with spiritual guided imagery and music for coping and resilience of cancer patients undergoing chemotherapy. 


\section{Methods and Equipment}

\subsection{Design}

The design of this research was a quasi-experiment. The treatment group received combination PMR therapy with SGIM as well as treatment and routine nursing actions from the hospital, while the control group received routine medication and nursing actions from the hospital.

\subsection{Setting}

The sample in this study were 62 respondents (31 control groups and 31 treatment groups). The sampling technique used a purposive method. This research was conducted at Raden Mattaher Hospital Jambi, Indonesia for 3 months. The inclusion criteria in this study were 1) patients with a cancer diagnosis who were undergoing chemotherapy, 2) ages 17-65 years, 3) cancer patients undergoing chemotherapy for a maximum of 3 chemotherapy sessions, 4) willingness to follow the research process to completion. Meanwhile, the exclusion criteria of this study were patients who had been given PMR or SGIM and cancer patients who had chemotherapy who had complications from more than 2 comorbidities.

\subsection{Procedure}

The procedure in this study begins with the administrative and licensing stages at the research location. This research was assisted by enumerators with Registered Nurse (RN) qualifications who had been given an explanation regarding the research process. In the early stages of the study, a pretest was conducted to determine the resilience and coping of respondents in both groups. Furthermore, the intervention was given after the patient had chemotherapy. Interventions take place in a quiet and comfortable room. Then PMR intervention was given for 15 minutes and continued with SGIM therapy, which was given in the form of a recorded form of spiritual motivation such as words of motivation and prayer compiled with music. The SGIM intervention consists of five phases, namely, the first phase ( 3 minutes early) is a prelude; in this phase, the patient is asked to bring up complaints that are being felt, for example, physical and psychological problems related to cancer, before entering the subconscious mind. The second phase ( 2 minutes) is induction; in this phase, the therapist gives verbal suggestions to relax the patient's body and prepares the patient to listen to music along with imaginary 
spiritual guidance. The third phase (10-15 minutes) is the classic music experience; in this phase, the patient is played music along with the guidance of spiritual imagination in the form of spiritual power (sincerity, confidence, gratitude, patience, and focus). The goal is to neutralize the psychological reversal. The fourth phase ( 5 minutes) is the postlude phase by listening to positive suggestions that make the patient's body more relaxed and refreshed, then followed by process of a few seconds to bring the patient back to its original state and open the eyes. Combined PMR and SGIM interventions were repeated everyone week for three times and then evaluated to retrieve posttest data.

\subsection{Instrument}

The tools and materials used to provide PMR and SGIM interventions are audio files, modules, booklets, and MP3, as well as notebooks for control and evaluation of actions held by the patient. The audio for SGIM is made different for each religion (Islam, Protestant, and Catholic). The prayer words in the spiritually guided imagery script are made by experts (pastors, priests, and clerics) with a master's education qualification.

Resilience was measured using The-14 items Resilience Scale (14). This instrument includes Equanimity (a balance of perspectives on a person's life), Meaningfulness (the understanding that life has deep meaning and value), Perseverance (the ability to move forward after a setback), Self-reliance (the belief that individuals have the skills needed and are aware of their limitations), and Existential aloneness (the awareness that each individual has a unique way of life). The instrument with a reliability of 0.91 , and significant at $p \leq 0.01$. The questionnaire uses a Likert scale of 1 to 7 (strongly disagree - strongly agree). The minimum value is 14 , and the maximum is 98 . The resilience category is very high (90), high enough (82-90), relatively low (65-81), low (57-64), and very low $(<57)$ $(15,16)$.

The Cancer Coping Questionnaire was used to measure the respondent's coping rate (17). The instrument consists of 21 items and two general questions related to stress and anxiety related to cancer. Items 1- 14 with questions about coping, positive focus, distraction, and planning. Items 15-21 represent an assessment of the interpersonal scale. Respondents were asked to determine four answer options ranging from "very often" often, "sometimes" and "never." This measuring instrument has an internal consistency of 0.87 for the individual scale and 0.82 for the interpersonal scale. Retry reliability is 0.90 for the Individual scale and 0.84 for the Interpersonal scale. 


\subsection{Analysis}

The data in this study were analyzed using the General Linear Model Repeated Measures (GLM Repeated Measures) test to determine the differences in coping and resilience values in the intervention group with the control, which was measured more than once.

\subsection{Ethical Consideration}

The research ethics committee approved the research protocol of the Health Polytechnic of the Ministry of Health Jambi. The Health Polytechnic Jambi No. LB.02.06 / 2/148/2019.

\section{Results}

GLM repeated measure analysis showed a p-value $<0.05$. The results of this analysis indicate that, in general, the combination of PMR therapy with SGIM has a significant effect on changes in coping and resilience of cancer patients undergoing chemotherapy. The results of this study also showed that the patient's coping began to form at the end of the first week, the second week, and the end of the third week. This can be seen from the comparison of the p-value between the treatment group and the control group. GLM test repeated measure coping and resilience $p$-value $=0.000$. Tests of Within-Subjects Effects Coping and resilience $p$-value $=0.000$. Changes in patient resilience only occurred at week two and week three after the administration of therapy. This situation shows that the formation of resilience in cancer patients undergoing chemotherapy begins with the shape of a coping mechanism (Table 1).

Table 2 shows the mean difference between coping scores and resilience $(p<0.05)$. This indicates that there is a significant difference in coping scores and resilience between measurements after PMR and SGIM measures. The results of the GLM repeated-measure analysis showed that the average coping score and resilience in each group in each size had a significant difference with $p=0.000$. This shows that there is a significant effect of combination therapy between PMR and SGIM on coping and resilience of cancer patients undergoing chemotherapy in the treatment group at each measurement time, whereas in the control group treatment and routine care from the hospital, the patient gets a significant effect on coping scores and resilience. 
TABLE 1: Analysis of the Difference of the Effect of Combination of PMR and SGIM on Coping and Resilience of Cancer Patients Undergoing Chemotherapy

\begin{tabular}{|c|c|c|c|c|c|c|c|}
\hline Variable & Time & Group & $\mathbf{n}$ & Mean & SD & $95 \% \mathrm{Cl}$ & $\mathbf{p}$ \\
\hline \multirow[t]{12}{*}{ Coping } & Pretest & Treatment & 30 & 54.90 & 4.75 & & \\
\hline & & Control & 30 & 56.50 & 4.49 & $-3.988-0.788$ & 0.185 \\
\hline & & Delta & & -1.6 & 0.26 & & \\
\hline & Week 1 & Treatment & 30 & 59.57 & 4.01 & & \\
\hline & & Control & 30 & 57.53 & 3.43 & $0.080-3.987$ & 0.042 \\
\hline & & Delta & & 2.04 & 0.58 & & \\
\hline & Week 2 & Treatment & 30 & 63.83 & 2.68 & & \\
\hline & & Control & 30 & 59.43 & 2.50 & $3.061-5.739$ & 0.000 \\
\hline & & Delta & & 4.04 & 0.18 & & \\
\hline & Week 3 & Treatment & 30 & 66.93 & 2.45 & & \\
\hline & & Control & 30 & 62.93 & 2.18 & $2.802-5.198$ & 0.000 \\
\hline & & Delta & & 4.00 & 0.27 & & \\
\hline \multirow[t]{12}{*}{ Resilience } & Pretest & Treatment & 30 & 67.70 & 5.09 & & \\
\hline & & Control & 30 & 68.73 & 4.62 & $-3.547-1.481$ & 0.414 \\
\hline & & Delta & & -1.03 & 0.47 & & \\
\hline & Week 1 & Treatment & 30 & 71.97 & 3.97 & & \\
\hline & & Control & 30 & 71.67 & 3.70 & $-1.683-2.283$ & 0.763 \\
\hline & & Delta & & 0.3 & 0.27 & & \\
\hline & Week 2 & Treatment & 30 & 76.87 & 2.97 & $0.687-4.113$ & 0.007 \\
\hline & & Control & 30 & 74.47 & 3.63 & & \\
\hline & & Delta & & 2.4 & -0.66 & & \\
\hline & Week 3 & Treatment & 30 & 79.93 & 3.48 & $1.167-4.966$ & 0.002 \\
\hline & & Control & 30 & 76.87 & 3.86 & & \\
\hline & & Delta & & 3.06 & -0.38 & & \\
\hline
\end{tabular}

\section{Discussion}

\subsection{The Effect of Combination of Progressive Muscle Relaxation with Spiritual Guided Imagery and Music on Coping of Cancer Patients Undergoing Chemotherapy}

The results showed the effect of the combination of PMR and SGIM on coping in cancer patients undergoing chemotherapy. This situation is due to the provision of PMR therapy combined with SGIM to increase relaxation and comfort through the suppression of stressors that vary as a result of cancer diagnosis and chemotherapy. The results of this study are in line with several studies that show the effect of PMR and GIM and a combination of both in reducing various problems related to cancer diagnosis and chemotherapy. The combination of PMR and Guided Imagery could reduce anxiety and 
TABLE 2: Pairwise Comparisons of the Effect of Combination of PMR Therapy with SGIM on Coping and Resilience of Cancer Patients Undergoing Chemotherapy

\begin{tabular}{l|l|l|l|l|l|}
\hline & Time & Mean & p & \multicolumn{2}{c|}{$95 \%$ Cl } \\
\hline Variable & & & & Min & Max \\
\hline Coping Score (Week 1) & Pretest: Coping & 2.850 & 0.000 & 2.039 & 3.661 \\
\hline Coping Score (Week 2) & Pretest: Coping Score (Week & 5.933 & 0.000 & 4.622 & 7.244 \\
& 1) & 3.083 & 0.000 & 2.118 & 4.049 \\
\hline $\begin{array}{l}\text { Coping Score (Week 3) } \\
\text { (posttest) }\end{array}$ & Pretest: Coping Score (Week & 9.233 & 0.000 & 7.443 & 11.024 \\
& 1) & 6.383 & 0.000 & 4.881 & 7.885 \\
\hline Resilience Score (Week 1) & Pretest: Resilience & 3.300 & 0.000 & 2.394 & 4.206 \\
\hline Resilience Score (Week 2) & Pretest: Resilience Score & 3.600 & 0.000 & 2.665 & 4.535 \\
\hline (Week 1) & 7.450 & 0.000 & 6.081 & 8.819 \\
\hline $\begin{array}{l}\text { Resilience Score (Week 3) } \\
\text { (posttest) }\end{array}$ & $\begin{array}{l}\text { Pretest: Resilience Score } \\
\text { (Week 1) }\end{array}$ & 3.850 & 0.000 & 2.959 & 4.741 \\
\hline & Resilience Score (Week 2) & 2.733 & 0.000 & 1.735 & 3.731 \\
\hline
\end{tabular}

improve mood in parents whose children are being treated with cancer in the hospital (11). PMR can reduce depression, anxiety, and length of care in breast cancer patients after undergoing radical mastectomy (10). Music therapy and guided visual imagery have a positive effect on reducing anxiety, nausea, and vomiting, in chemotherapy patients (18). The findings of some of these studies support the results of this study that the combination of PMR with SGIM can reduce psychological stress that arises as a result of cancer diagnosis and chemotherapy. The researchers interpret the success of combination therapy between PMR and SGIM in the management of steres as an adaptive coping process for patients.

PMR is part of relaxation therapy that is used as a coping skill that teaches patients when and how to exercise relaxation and comfort under conditions that can cause anxiety (8). This muscle relaxation technique is reported to be effective in reducing muscle tension in the body. Muscle relaxation can directly inhibit anxiety and reduce nausea and vomiting that is usually triggered by tense muscles. Some researchers have suggested that PMR can serve as a relaxation method for patients undergoing chemotherapy (19). Meanwhile, SGIM therapy itself is a healing process carried out with a spiritual approach or a way to neutralize and dissolve mental patterns that contain diseases, physical and mental disorders, which aim to foster joy, security, peace of mind, and guidance for the emergence of the belief that healing comes from God through the provision of spiritual motivation by listening to a guided imaginary recording accompanied by appropriate spiritual music. 


\subsection{The Effect of the Combination of Progressive Muscle Relax- ation with Spiritual Guided Imagery and Music on the Resilience of Cancer Patients Undergoing Chemotherapy}

The results showed the effect of the combination of PMR and SGIM on the resilience of cancer patients undergoing chemotherapy at Raden Mattaher Hospital Jambi. Basically, the combination of PMR and SGIM does not directly increase patient resilience but requires a gradual process. Resilience is formed as a result of the patient's good adaptation mechanism. The adaptation referred to here is a constructive coping process in overcoming problems that arise as a result of the patient's cancer diagnosis and chemotherapy. Research facts show that resilience is only formed in the second and third weeks after being given a combination of PMR with SGIM, while the coping mechanism is formed from the first week after being given the intervention. This means that the formation of resilience in cancer patients undergoing chemotherapy in this study begins with the formation of constructive coping from the patient.

The results of this study are in line with the research (6) regarding resilience in cancer patients where it is known, the coping mechanism has a significant effect on resilience, and further he concluded that the adaptive coping mechanism of cancer patients could increase their resilience in carrying out chemotherapy. According to (20) In essence, resilience refers to positive adaptation, or the ability to maintain or regain mental health despite adversity. Resilience is a dynamic process that includes positive adaptation in the context of significant difficulties, contains hazards, and can change over time and in different environments. (21).

The results of the study also showed that the average patient resilience score was in the fairly low category even though they had been given intervention. In addition, it is also known that individuals who have high resilience have high scores on the aspects of meaningfulness, equanimity, perseverance, self-reliance, and existential aloneness compared to others. In terms of meaningfulness, perseverance, and equanimity, it is known that patients have a strong determination to recover. They have the confidence to be able to go through difficult times because they have experienced something more difficult before. In the aspect of self-reliance and existential aloneness, it is known that even though they suffer from cancer, they believe that their life has meaning. In difficult conditions, they can take important steps or decisions calmly. 


\subsection{Differences in coping and resilience of cancer patients under- going chemotherapy after being given Progressive Muscle Relaxation Combination Therapy with Spiritual Guided Imagery and Music}

The results showed that there were differences in the effect of the combination therapy of Progressive Muscle Relaxation with Spiritual Guided Imagery and Music on the coping and resilience of cancer patients undergoing chemotherapy. This difference lies in the increase in the mean score of coping and higher resilience in the treatment group compared to the control group. This happened because, in addition to giving intervention only to the treatment group, it also occurred as a result of the respondents who did this therapy quickly adapting to the spiritual motivation that was on the SGIM record. The words in the SGIM record have the power to cultivate spiritual power, namely sincerity, confidence, gratitude, patience, and sincerity in dealing with cancer. Based on the analysis of the spiritual practices of the patient, the average patient has moderate to high spiritual aspects. This spiritual aspect is a protective factor that supports increased patient resilience.

Spiritual needs are the need to maintain or restore faith, fulfill religious obligations, and the need for forgiveness or forgiveness (22). There have been many studies related to spiritual response in adults who have cancer. Some of the spiritual aspects studied include the quality of spiritual life, spiritual needs, hope, religious coping, self-transcendence, and religious practice (especially prayer) (13). Besides containing spiritual motivation, this SGIM recording also has prayers in it.

One aspect that makes this therapy different from others is that this therapy is a form of treatment that involves aspects of mind, body, and spirit. The mind and body are played by PMR therapy, while the spiritual aspect is obtained from the SGIM therapy. The combination of these two therapies is thought to reduce and even reduce negative emotional blocks that exist in patients as a result of stressors received during chemotherapy and also increase spiritual power. The prayer in this therapy raises excellent hope and confidence to recover and endure difficulties, or it can be said to be able to increase positive adaptation mechanisms that will have an impact on patient resilience. According to (23) spiritual power (sincerity, confidence, gratitude, patience, and gravity) will release all negative emotional blocks that exist in a person. It can be said that the essence of SGIM is actually very simple, that is when listening to this recording, the patient changes all the negative things in him into something positive, such as changing feelings of guilt with repentance, being angry with forgiveness, sadness 
with tawakal, being disappointed with sincerity, losing with the patient, arrogant with gratitude.

\section{Conclusion}

This finding is an input for the Indonesian Government to provide information on the combination of Progressive Muscle Relaxation therapy with Spiritual Guided Imagery and Music in cancer programs to provide new knowledge for medical-surgical nurses to provide new interventions specifically to improve coping and resilience of cancer patients undergoing chemotherapy. The government and health workers are expected to consider these findings that can be used as interventions to enhance coping and resilience.

\section{Funding}

None

\section{Acknowledgement}

The researchers would like to thank STIKES Harapan Ibu Jambi, Director of Raden Mattaher Jambi Hospital, Head of Room and Room Nurse for all her valuable support and also thank all respondents who participated in this research.

\section{Conflict of Interest}

None

\section{References}

[1] Airley, R. (2009). National Cancer Institute The NCl Consumers' Cancer Dictionary for Peer Review. Oxford: John Wiley \& Sons Ltd.

[2] Suzana, Y., Fatin, N. and Nina, K. D. R. (2016). Depressive Symptoms among Cancer Patients Undergoing Chemotherapy. Social and Behavioral Sciences, issue 234, pp.185-192.

[3] Kirana, L. (2016). Dukungan Sosial Dan Resiliensi Pada Pasien Kanker Payudara (Studi Kasus Pada Pasien Kanker Payudara Yang Sedang Menjalani Kemoterapi). 
Psikoborneo, vol. 4, issue 4, pp. 829-837.

[4] Min, J., et al. (2013). Psychological Resilience Contributes to Low Emotional Distress in Cancer Patients. Support Care Cancer, issue 21, pp. 2469-2476.

[5] Ahadi, H., Delavar, A. and Rostami, A. M. (2014). Comparing Coping Styles in Cancer Patients and Healthy Subjects. Social and Behavioral Sciences, issue 116, pp. 34673470.

[6] Yunitasari, E. (2016). The Development of Coping-Roy's Adaptation Nursing Care Model to Increase the Resiliency of Post Radikal Hysterectomy + BSO Cervical Cancer Patients who Received Chemotherapy. Universitas Airlangga.

[7] Loprinzi, E. C., et al. (2011). Stress Management and Resilience Training (SMART) Program to Decrease Stress and Enhance Resilience Among Breast Cancer Survivors: A Pilot Randomized Clinical Trial. Clinical Breast Cancer, vol. 11, issue 6, pp. 364-368.

[8] Snyder, M. and Lindquist, R. (2006). Complementary / Alternative Therapies in Nursing. ( $5^{\text {th }}$ ed.). New York: Springer Publishing Company.

[9] Mohamad-rodi, I, et al. (2013). Impact of Applied Progressive Deep Muscle Relaxation Training on the Health Related Quality of Life among Prostate Cancer Patients - A Quasi Experimental Trial. Preventive Medicine, issue 57, pp. 40-43.

[10] Kaina, Z., et al. (2015). A Clinical Randomized Controlled Trial of Music Therapy and Progressive Muscle Relaxation Training in Female Breast Cancer Patients after Radical Mastectomy: Results on Depression, Anxiety and Length of Hospital Stay. European Journal of Oncology Nursing, vol. 19, issue 1, pp. 54-59.

[11] Theologia, T., Andreas, C. and Evridiki, P. R. (2017). Effectiveness of a Relaxation Intervention (Progressive Muscle Relaxation and Guided Imagery Techniques) to Reduce Anxiety and Improve Mood of Parents of Hospitalized Children with Malignancies: A Randomized Controlled Trial in Republic of Cyprus and Greece. European Journal of Oncology Nursing, issue 26, pp. 9-18.

[12] Yulianto, A. (2012). Spiritual Healing. Jakarta: HPA.

[13] Johnston, T. E., Cheryl, P. and Oladele, J. (2015). Spirituality and Spiritual Care of Adolescents and Young Adults with Cancer. Seminars in Oncology Nursing, vol. 31, issue 3, pp. 227-241.

[14] Wagnild, G. (2003). Resilience and Successful Aging Comparison Among Low and High Income Older Adults. Journal of Gerontological Nursing, vol. 29, issue 12, pp. $42-49$. 
[15] Oliveira, A., et al. (2014). Confirmatory Factor Analysis of the Resilience Scale Short form in a Portuguese Adolescent Sample. Social and Behavioral Sciences., issue 165 , pp. 260-6.

[16] Elisavet, N., et al. (2017). The Greek Version of the Resilience Scale (RS-14): Psychometric Properties in three Samples and Associations with Mental Illness, Suicidality, and Quality of Life. Journal of Psychology and Clinical Psychiatry, vol. 7, no. 5.

[17] Moorey, S., Frampton, M. and Greer, S. (2003). The Cancer Coping Questionnaire: A Self-Rating Scale for Measuring the Impact of Adjuvant Psychological Therapy on Coping Behaviour. Psychooncology, vol. 12, issue 4, pp.331-44.

[18] Karagozoglu, S., Tekyasar, F. and Yilmaz, F. (2012). Effects of Music Therapy and Guided Visual Imagery on Chemotherapy-Induced Anxiety and Nausea - Vomiting. Journal of Clinical Nursing, issue 22, pp. 39-50.

[19] Helen, C. (2019). Progressive Muscle Relaxation. Complement Altern Med Cancer. Retrieved November 28, 2019 from http//www.cam-cancer.org/The-Summaries/ Mind-body-Interv.

[20] Herrman, H., et al. (2011). What Is Resilience? Can The Canadian Journal of Psychiatry, vol. 56, issue 5, pp. 258-265.

[21] Fletcher, D. and Sarkar, M. (2013). Psychological Resilience A Review and Critique of Definitions, Concepts, and Theory. European Psychologist, vol. 18, issue 1, pp. 1223.

[22] Setiadi \& Irawandi, D. (2017). Pendidikan Agama Islam Untuk Tenaga Kesehatan (Teori dan Aplikasi Praktek Bagi Mahasiswa dan tenaga Kesehatan di Tempat Praktek). Surabaya: Indomedia Pustaka.

[23] Zainuddin, A. (2012). SEFT for Healing, Success, Happiness, and Greatness. Jakarta: Afzan Publishing. 